\title{
Erectile dysfunction and caverno-venous leak disease
}

\author{
Herwig $\mathbf{R}^{*}$ \\ Men's Health Clinic, Wollzeile 1, 1010 Vienna, Austria
}

\begin{abstract}
Erectile dysfunction is an increasing issue, especially in young man. Whereas the current treatment strategies are mostly focused on older men, young patients are seeking more for a longer lasting or definitive solution, rather than a life-long medical treatment. Possibly, this is a reason why currently $70 \%$ of men with erectile dysfunction are not under treatment.This aspect becomes also a socioeconomic relevance, as this generation of patients can also be called the backbone of most societies. As a logical consequence the treatment strategies in different stages of life should be reviewed.

Whereas various chronic disorders have been reported to be associated with elevated rates of ED including depression, diabetes, cardiovascular and neurological diseases in older men, the young generation is more suffering from vascular problems which affects the storage capacity of the penis.

The aim of this work is to review the efficiency of newly developed minimal invasive treatment strategies for this blood storage problem, causing erectile dysfunction which is mostly described as caverno-venous leakage. The systematic review of the literature reveals a significant number of recent studies dealing with new minimal invasive methods to provide a potential solution of caverno-venous leakage. Even long-term results reported demonstrate considerable improvement of erectile dysfunction caused by this condition. Furthermore, 3D-Computed tomography cavernosography (CT-cavernosography) is a new technology, which can provide highresolution images of venous drainage from any angle and shows to be very helpful for both the diagnosis of corporal veno-occlusive dysfunction and the anatomical study of the human penile venous system. The application of this technology may also lead to better strategies in venous leak treatment.
\end{abstract}

In summary, over 30 published studies could be found in the literature with constantly good results after caverno-venous leak treatment. Altogether, 13 comparable studies including 538 patients could be found, in which a mean short-term success rate of almost $80 \%$ and a mean long term success rate of $74 \%$ was achieved. None of the studies described major complications. These encouraging results should lead to reconsider or current strategy in treatment of erectile dysfunction in young men.

Erectile dysfunction is a big issue in various populations. Over $30 \%$ of young man are suffering from this condition with an increasing tendency [1].

Various chronic disorders have been reported to be associated with elevated rates of ED including depression, diabetes, and cardiovascular and neurological diseases. Such disorders are more common in the elderly, which may partially explain the elevated prevalence of ED in men over $60 \mathrm{yrs}$ of age. In younger patients the reason for erectile dysfunction is more a vascular problem which affects the storage capacity of the penis. Currently, up to $70 \%$ of men with ED are not treated. However, so many men experience considerable distress from their condition, that the increasing awareness of ED as well as the availability of noninvasive treatments may result in a greater proportion of patients seeking treatment, and eventually regaining satisfaction with their sex life [2].

Furthermore, it is commonly discussed that there is also a strong dependency of erectile dysfunction on divorce rate, as the three mayor reasons for divorce are related to frequent and satisfying sexual intercourse, which is an important factor in interpersonal relationship.

No sex, no kids, no-one to pay the social insurance in the future. In this view, the point becomes additionally a significant sociopolitical relevant issue.

Treatment schemes are currently mainly focused on dealing with the relevant chronic disorders in elderly patients. The current first choice treatment option is applying a PDE5-Inhibitor [3], which is dealing with the symptom only and has a success rate of maximum $70 \%$. But, several reports demonstrate a remarkably lower success rate. Virag et al. [4] found, that of 157 patients, who had completed his initially study, the efficacy of and satisfaction with sildenafil was considered good in only $31.84 \%$, fair in $29.29 \%$ ), and bad in $38.85 \%$ of the patients. In case of significant venous leakage disease, no patient reported a good treatment result with sildenafil and $83 \%$ reported a bad response [4].

Additionally, one has to be aware that PDE5-inhibitor therapy is not a curative treatment. In case of early onset of erectile dysfunction, it can mean a lifelong treatment with all the known disadvantages of the therapy. Additionally, for several reasons, treatment rates of ED are clearly lower than the prevalence rates. One major reason is the fact, that most health-care payors are currently excluding reimbursement of this medically and socioeconomic condition [2].

Furthermore, if cavernosography is used to define the presence of a venous leakage, a condition where the loss of blood from the penis is lying over the supply level, in impotent patients 86 per cent fall into the category of venous leakage [5]. Other studies report about a percentage of $89 \%$ venous leakage in case of organic erectile dysfunction [6]. These data support recent observations that there is a high incidence of venous leakage as defined by these criteria in the young men population with organic impotence [5].

Correspondence to: Priv. Doz. Dr. med. univ. Ralf Herwig, Men's Health Clinic Wollzeile 1, 1010 Vienna, Austria, E-mail: dr.herwig@dr-herwig.com

Received: December 20, 2017; Accepted: January 11, 2018; Published: January 15,2018 
Interestingly, venous leak disease as cause for erectile dysfunction is, in no case, only a condition found in human. Several reports demonstrate an erectile dysfunction due to corporo-venous insufficiency in various animal species, including bulls and boars [7-10].

It can be found that clinically bulls can also be unable to achieve erection when stimulated with an electroejaculator and in natural breeding trials. Vascular shunts can be located as cause of erectile dysfunction by serial contrast radiography of the corpus cavernosum penis. If surgical correction of the shunts is attempted by wedge resection of the tunica albuginea, this surgical correction is successful in $50 \%$ of the treated animals and the bulls can be returned to service [10].

Simple isolated ligation of the deep dorsal vein in humans for the permanent cure of erectile dysfunction due to venous leak is up to now not recommended, due to some reported low long-term success rates $[3,11,12]$.

The only in this context cited article in the EAU guidelines 2010(3) is from the group of Wespes [12]. Unfortunately, this article is not qualified to substantiate such a statement. Of 130 patients with vascular erectile dysfunction who underwent various surgical procedures, only 11 patients were treated with venous resection. For further evaluation, only 7 patients were eligible after 48 months in this group of which only one patient reported about sexual satisfaction. No IIEF-Score or QOL evaluation was evaluated before and/or after surgery. A reliable guideline statement about the successfullness of this intervention can not be seriously made from this number of patients with this evaluation method. Nevertheless, $100 \%$ success was stated for penile revascularisation in two out of two patients. The authors assert, that this finding is evidence enough to recommend penile revascularisation for young patients with traumatic arterial lesions [12]. This statement was adopted into this guideline version, too.

Another, more serious study was performed earlier in the 1999 by Popken et al. In this evaluation ligature and resection of the superficial and deep veins of the penis (DPVL) was performed in 122 patients. All patients were non-responders to intracavernosal injection of alprostadil (SKAT) [11], which is a very difficult initial starting point to prove the effectiveness of such a procedure. Twenty-six per cent had ectopic veins, $38 \%$ a leakage through the crural veins and $24 \%$ a glandular or spongiosal shunt. After the 70-month follow-up, 14\% of the 122 patients were able to achieve an adequate spontaneous erection and $19 \%$ also responded to SKAT. Taking in account that these patients are strong candidates for a penile implant, the success rate of $33 \%$ seems to be excellent in this setting [11]. In a third of the patients natural erections could be regained and maintained for a long time. This is an important aspect, because in many countries penile implants are not covered by insurance companies and therefore most of these patients can not afford this expansive therapy option.

In the most recent guidelines of the EAU from 2016 [13] the afore mentioned literature citation is replaced by a Meta-Analysis of Sohn et al. [14]. The recommendation of the EAU is still: „Vascular surgery for veno-occlusive dysfunction is no longer recommended because of poor long-term results.,

The cited literature to state this, in contrast, does not at all support this recommendation, because it states that "While caverno-venous occlusion disease (CVOD) surgery is still considered investigational, it may be offered in special situations." [14-27]. Furthermore, the literature processed in this publication of Sohn et al. is from 1997 to 2005 and does, therefore, not reflect the current state of research.
The members of the 3rd International Consultation on Sexual Medicine in Paris 2009 published their conclusions and recommendations in two recent articles in 2010 [28, 29].

In this context, a compilation of outcome data of simple ligation techniques published until 2005 was discussed [14].

In the here revised literature a wide variety of success rates was found. For the authors, no single operative technique seemed to be superior to others, and a steep decline of success has to be noted with length of follow-up in single ligation procedures. But, the authors stated, that young patients with site-specific congenital, posttraumatic or post-inflammatory leaks may be considered for vein ligation with informed consent. The choice of operation offered should be decided on available wisdom and infrastructure, the experience and preference of the operating surgeon, and the basis of the site, nature, and size of the leak [14].

In contrast to these ancient findings, various modified and improved technologies with much better short- and long-term outcome have been recently described.

The first report of arterialization of the deep dorsal vein was published in 1981 by Virag et al. [15] with a long-term success rate of $80 \%$.

Additionally, a multidisciplinary approach with emphasis on hemodynamic tests was used to diagnose 421 patients with arteriogenic, venogenic or mixed arteriogenic/venogenic impotence who underwent a vascular surgical procedure. With an average followup of nearly five years, approximately $50 \%$ of patients were cured and an additional $20 \%$ were improved [16]. After an average follow-up of 3 years, patients in the venous ligation group $(n=110)$ in $68 \%$ of the cases had good results. In the deep dorsal vein arterialisation group $(n=153) 74 \%$ of the patients reported good results [16].

Due to the fact, that more recent literature dealing with new concepts of minimal invasive technologies and modern diagnostic tools our aim was to present an overview over the results from this more recent studies.

A structured review of English-language articles on PubMed published till 2017 coupled with examination of tables of contents of high-impact journals to identify articles related to venous leak treatment was performed. These articles were appraised for their importance to medicine.

Current publications explored, that 3D-CT cavernosography can provide high-resolution images of venous drainage from any angle. Therefore, the authors conclude that the images obtained by $3 \mathrm{D}-\mathrm{CT}$ cavernosography are very helpful for both the diagnosis of corporal veno-occlusive dysfunction and the anatomical study of the human penile venous system and may lead to better strategies in venous leak treatment [17-21].

Interrestingly, penile venous surgery with ligation of the crura for venous leakage has revealed good long term results and high patient satisfaction. The unanimously stated conclusion from these studies is, that this technique should be offered in young men with primary cavernosal erectile dysfunction. Young patients with normal penile arterial system and no risk factors such as diabetes had the best chance to improve erection and have a good postoperative success [22-27].

From 2006 on to the present time, several further publications on minimal invasive venous leak procedures for ED have been published. 
Basche et al. described a technique of retrograde embolisation carried out via the femoral vein by coaxial technique using HistoacrylLipiodol solution in order to embolise all angiographically identified insufficient veins. At one year follow up all patients treated still achieved spontaneous erections without any additional medical treatment [30].

Cayan et al. described a highly selected group of young patients (mean age 34.6 years) with primary venogenic ED, who were submitted to extended venous ligations including crura ligation with umbilical tapes(22). Mean postoperative follow-up was 42.9 months and IIEF scores were used for success evaluation. IIEF- 5 score rose statistically significant from 6.7 to 16.3 and patient satisfaction was complete in $57.7 \%$.

Hsu and coworkers described a venous stripping procedure in selected patients with isolated CVOD excluding untreated systemic disease. Of 341 patients 178 patients were submitted to this procedure and further 163 were left without surgery [31]. IIEF-5 score increased from 9.7 to 21.6 after a mean follow-up of 7.7 years in the operated group, while patients under observation only showed a decrease of IIEF-5 score from 10.4 to 7.9. Operation time ranged from 2.1 to 5 hours and local anesthesia was used with additional acupuncture.

All these publications denied serious complications, as well as penile shortening or loss of sensation.

Most recently an article on the outcome of crural ligation for isolated crural venous leakage in 14 young patients was published by a study group from the Memorial Sloan Kettering Cancer Center and Columbia University [23]. The IIEF score was raised from 18 to 24 after 1 year of follow-up. Seventy-one percent experienced unassisted post-operative sexual intercourse. The authors conclude that crural ligation may be a promising approach in those rare young patients with primary venogenic ED and isolated crural leakage.

Vale et al. reported about a high long-term outcome in $63.6 \%$ after ligation of the deep dorsal vein [32]. In a further study from Chen a highly significant change in IIEF score after long-term observation was stated for patients who underwent deep dorsal vein stripping [33]. Very recently Zang reported about very good long-term success rates after deep dorsal vein embedding (100\%), respectively [34].

A further newly described method is the embolisation technique. During this aproach, either antegrade or retrograde venous closure can be performed [30, 35-43].

Results from these studies are demonstrated in (Table 1).

Unlike in urology, in general surgery, there are clear guidelines for the treatment of varicous veins [44]. One of the important principles is the proximal compression of the vein, which is treated with a sclerosing/emolisation agent. The reason is lying in the mode of action in these agents. The longer and concentrated the substance can stay at the venous wall, the more effective is the sclerosing action of the medication. If applied as microfoam, it can be even more effective, due to better visibility under X-ray and more homogeneous contact to the endothelium [45-47].

Another reasons responsible for the good long-term outcome of the procedure might be the application of a Computed tomography cavernosography with 3D-reconstruction.

The superior visualization of the complex venous draining system in a 3D-CT cavernosography before (Figure 1) and after sclerotherapy (Figure 2) was first described by Virag [7] and could be verified by Uhl [20] and $\mathrm{Xu}[48]$. The picture in figure 1 describes the complex situation

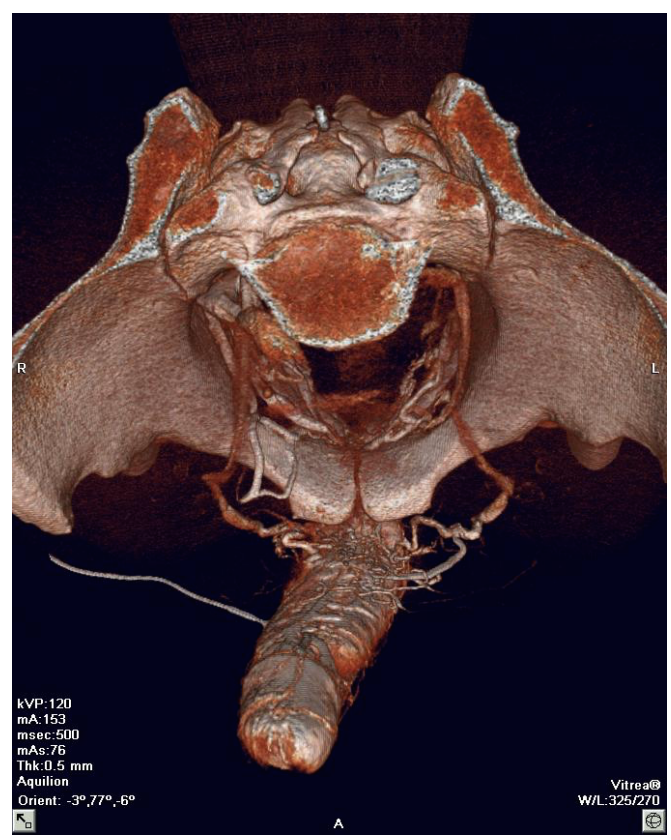

Figure 1. The superior visualization of the complex venous draining system in a 3D-CT cavernosography before sclerotherapy

in venous leakage disease and the need for a more complex renovation of the situation. It might also explain the fact, that neither simple ligation of penile veins, nor ligation of crural veins could sustainly solve the problem of venous leak disease. Furthermore, these pictures might reveal the up to now unexplained relation between erectile dysfunction and hemorrhoids [49] and possible erectile dysfunction after hemorrhoid sclerotherapy [50], due to the fact that the related veins are connected via the deep pelvic vein system. These results also demonstrate the urgent need to re-explore the veinous drainage system with new higher sophisticated techniques.

Therefore, this in many cases underlying combination of cavernosal and crural insufficiency should be addressed in one procedure to prevent early relapse [18].

In a very recent study of Herwig and Sansalone these aspects are respected in a newly described technique, which reaches the deep dorsal vein system, as well as the crural venous system [17, 46, 47].

When preparing the deep dorsal vein at the proximal penis shaft, the ligation of the vein distally closes the primary leak from the deep dorsal vein. In addition, the afore localized major leakage point revealed by $3 \mathrm{D}-\mathrm{CT}$ cavernosography can be closed by several distal and proximal ligations. Afterwards, a 5F-Angiokatheter is placed in the proximal part oft he vein. Under Valsalva-Maneuver, which has to be performed by the patients, the blood flow is reduced in the lower pelvis equal to the compression described in general surgery guidelines. When injecting polidocanol as a sclerosing agent during this time, the agent can stay longer at the venous wall and the effect of the sclerosing therapy is maximized. No residual crural or deep dorsal vein leakage could be detected after integrate combined ligation of the deep dorsal vein and antergrade sclerotherapy procedure (Figure 2). Therefore, this method is providing a therapy for deep dorsal vein and crural venous leakage in a minimal invasive setting at the same time [17, 46, 47].

With this newly described technique, at 3 month follow-up 77 out of 96 patients $(80.21 \%)$ reported to have erections sufficient for vaginal insertion without the use of any drug or additional device. 
Table 1. Literature of embolisation technique used in treatment of erectile dysfunction $(17,22,30,32,34-38,41,47,52,53)$.

\begin{tabular}{|c|c|c|c|c|c|}
\hline Author & Year & Method & Number o Pat & short (3 months) & long (>12 months) \\
\hline Schild & 1993 & embolisation retrograde & 53 & $\mathrm{n} / \mathrm{s}$ & $75.5 \%$ \\
\hline Vale & 1995 & ligation & 27 & $70 \%$ & $63.6 \%$ \\
\hline Nakata & 2000 & antegrade Embolisation - Ethanol & 23 & $87 \%$ & $78 \%$ \\
\hline Peskircioglu & 2000 & embolisation- N-butyl cyanoacrylate & 32 & $\mathrm{n} / \mathrm{s}$ & $68.7 \%$ \\
\hline Miwa & 2001 & Sclerotherapy ethanol & 10 & $70 \%$ & $50 \%$ \\
\hline Basche & 2003 & retrograde Embolisation & 4 & $\mathrm{n} / \mathrm{s}$ & $100 \%$ \\
\hline Cayan & 2008 & Venous surgery and crural ligation & 26 & 0,731 & 64,5 \\
\hline Kutlu & 2009 & embolisation & 32 & yes & yes \\
\hline Zhang & 2009 & Embedding deep dorsal vein & 17 & 0,8235 & $\mathrm{n} / \mathrm{s}$ \\
\hline Aschenbach & 2013 & endovascular embolisation & 29 & 0,888 & $\mathrm{n} / \mathrm{s}$ \\
\hline Rebonato & 2014 & anterograde embolization & 18 & 0,81 & $\mathrm{n} / \mathrm{s}$ \\
\hline Herwig & 2015 & Sclerotherapy, airblock, valsalva & 96 & $80.21 \%$ & $72.73 \%$ \\
\hline \multirow[t]{2}{*}{ Carrino } & 2016 & Sclerotherapy, airblock, valsalva & 171 & $\mathrm{n} / \mathrm{s}$ & 0,906 \\
\hline & & & $\mathrm{n}=538$ & Mean $79,06 \%$ & Mean $73,74 \%$ \\
\hline
\end{tabular}

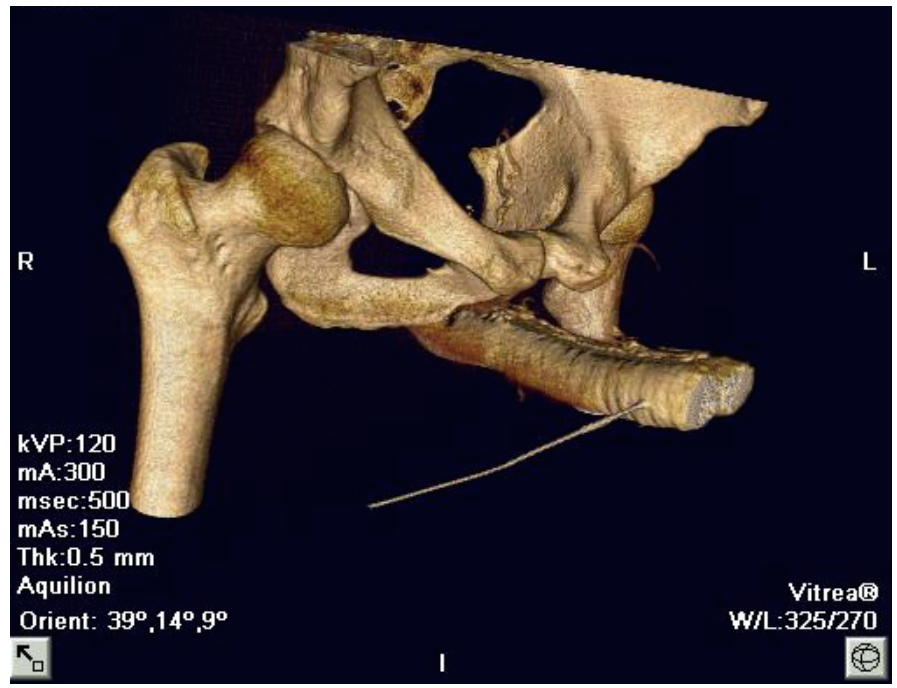

Figure 2. The superior visualization of the complex venous draining system in a 3D-CT cavernosography after sclerotherapy

Four $(4.17 \%)$ patients did not report any improvement. Follow up with color Doppler ultrasound and CT Cavernosography revealed a new or persistent venous leakage in $8(8.33 \%)$ of the patients. After a follow up of 12 months $(\mathrm{n}=22) 16(72.73 \%)$ patients still reported to have a strong enough erection for sexual intercourse. Four (18.18\%) patients used PDE5 inhibitors and 2 (9.09\%) patients did not report any change to their preoperative state. As before, the authors denied serious complications.

These data have been supported by a report of Carrino et al. who reported a success rate of over $90 \%$ in over 170 patients treated with this sclerotherapy treatment. Furthermore, the cure rate for erectile dysfunction was $77 \%$, which exceeds the effectiveness of PDE5inhibitor therapy by far [47] and offers a long-term cure of the problem.

These new and encouraging results in almost 540 patients show a short-term success rate of about $80 \%$ and long-term success in $73,7 \%$. Depending on the method applied there is a slight advantage towards a combination of ligation and antegrade sclerotherapy with $80 \%$ shortterm and 81,66\% long-term success rate in 267 patients.

These recent good results with this technique lead Rebonato et al. [51-53] to the statement, that even so, embolization techniques should be considered in all the cases of confirmed ED due to VOD, especially in young patients. Although the technique is not always successful restoring completely the erectile function, in most cases, the patients have a satisfactory erectile function just resorting to oral pharmacotherapy (PDE5 inhibitors), delaying the time to penile prosthesis.

Although further exploration in randomized controlled studies is needed, these results should lead to re-consider venous leakage treatment with these minimal invasive methods in therapy of erectile dysfunction. The described methods are minimally invasive, are carried out in local anesthesia and do not contain major risks or complications.

Possibly, a combined therapy model is needed to support these mostly young patients and prevent them at least partially from lifelong continuous medical treatment with all described disadvantages and complications.

\section{Reference}

1. Nguyen HMT, Gabrielson AT, Hellstrom WJG2 (2017) Erectile Dysfunction in Young Men-A Review of the Prevalence and Risk Factors. Sex Med Rev 5: 508-520. [Crossref]

2. Kubin, M., G. Wagner, and A. R. Fugl-Meyer. 2003. Epidemiology of erectile dysfunction. Int J Impot Res 15: 63-71.

3. Hatzimouratidis, Amar KE, Eardley I, Giuliano F, Hatzichristou D, et al. (2010) Guidelines on male sexual dysfunction: erectile dysfunction and premature ejaculation. Eur Urol 57: 804-814.

4. Virag R (1999) Indications and early results of sildenafil (Viagra) in erectile dysfunction. Urology 54: 1073-1077. [Crossref]

5. Rajfer J, Rosciszewski A, Mehringer M (1988) Prevalence of corporeal venous leakage in impotent men. J Urol 140: 69-71. [Crossref]

6. Beidaghian A, Beeniaz F (2001) The study of venous leakage in erectile dysfunction by cavernosometry and cavernosography: A case series in Sina Hospital. Tehran Univ Med J 59: 33-38.

7. Ashdown RR, David JS, Gibbs C (1979) Impotence in the bull: (1) Abnormal venous drainage of the corpus cavernosum penis. Vet Rec 104: 423. [Crossref]

8. Ashdown RR, Gilanpour H, David JS, Gibbs C (1979) Impotence in the bull: (2) occlusion of the longitudinal canals of the corpus cavernosum penis. Vet Rec 104: 598603. [Crossref]

9. Ashdown RR, Barnett SW, Ardalani G (1982) Impotence in the boar 2: Clinical and anatomical studies on impotent boars. Vet Rec 110: 349-356.

10. Young SL, Hudson RS, Walker DF (1977) Impotence in bulls due to vascular shunts from the corpus cavernosum penis. J Am Vet Med Assoc 171: 643-648.

11. Popken G, Katzenwadel A, Wetterauer U (1999) Long-term results of dorsal penile vein ligation for symptomatic treatment of erectile dysfunction. Andrologia $31 \mathrm{Suppl}$ 1: 77-82. [Crossref] 
12. Wespes E, Wildschutz T, Roumeguere T, Schulman CC (2003) The place of surgery for vascular impotence in the third millennium. $J$ Urol 170: 1284-1286. [Crossref]

13. Hatzimouratidis K, Giuliano F, Moncada I, Muneer A, Salonia A (2016) Guidelines on Erectile Dysfunction, Premature Ejaculation, Penile Curvature and Priapism. EAU

14. Sohn M, Hatzinger M, Goldstein I, Krishnamurti S (2013) Standard operating procedures for vascular surgery in erectile dysfunction: revascularization and venous procedures. J Sex Med 10: 172-179.

15. Virag R (1981) Unstable erection due to venous insufficiency. Diagnosis and surgical correction. 10 cases with a mean follow-up 12 months (author's transl)]. J Mal Vasc 6: $121-124$

16. Virag R, Bennett AH (1991) Arterial and venous surgery for vasculogenic impotence: a combined French and American experience. Arch Ital Urol Nefrol Androl 63: 95-100. [Crossref]

17. Herwig R, Sansalone S (2015) Venous leakage treatment revisited: pelvic venoablation using aethoxysclerol under air block technique and Valsalva maneuver. Arch Ital Urol Androl 87: 1-4.

18. Herwig R, Greilberger J, Weibl P (2017) CT Cavernosography and Penile Venous Leak. JOJ Urology \& Nephrology 3: 1-5

19. Kawanishi Y, Izumi K, Muguruma H, Mashima T, Komori M, et al. (2011) Threedimensional CT cavernosography: reconsidering venous ligation surgery on the basis of the modern technology. BJU Int 107: 1442-1446.

20. Uhl JF (2012) Three-dimensional modelling of the venous system by direct multislice helical computed tomography venography: technique, indications and results. Phlebology 27: 270-288.

21. Virag R, Paul JF (2011) New classification of anomalous venous drainage using caverno-computed tomography in men with erectile dysfunction. $J$ Sex Med 8: 14391444.

22. Cayan S (2008) Primary penile venous leakage surgery with crural ligation in men with erectile dysfunction. J Urol 180: 1056-1059. [Crossref]

23. Flores S, Tal R, O'Brien K, Mulhall JP (2011) Outcomes of crural ligation surgery for isolated crural venous leak. J Sex Med 8: 3495-3499. [Crossref]

24. Lue TF (1999) Surgery for crural venous leakage. Urology 54: 739-741. [Crossref]

25. Mulhall JP, Martin D, Ergin E, Kim F (2001) Crural ligation surgery for the young male with venogenic erectile dysfunction: technique. Tech Urol 7: 290-293. [Crossref]

26. Puech-Leão P, Reis JM, Glina S, Reichelt AC (1987) Leakage through the crural edge of corpus cavernosum. Diagnosis and treatment. Eur Urol 13: 163-165. [Crossref]

27. Rahman NU, Dean RC, Carrion R (2005) Crural ligation for primary erectile dysfunction: a case series. Elsevier 173: 2064-2066

28. Hellstrom WJ, Montague DK, Moncada I, Carson C, Minhas S, et al. (2010) Implants, mechanical devices, and vascular surgery for erectile dysfunction. $J$ Sex Med 7: 501523. [Crossref]

29. Montorsi F, Adaikan G, Becher E, Giuliano F, Khoury S, et al. (2010) Summary of the recommendations on sexual dysfunctions in men. J Sex Med 7: 3572-3588.

30. Basche S, Eger C, Elsebach K, Ulshofer B (2003) Veno-occlusive dysfunction as a cause of erectile impotence: therapy of venous leak with retrograde embolization of the internal pudendal vein. Vasa 32: 47-50.

31. Hsu GL, Hill JW, Hsieh CH, Liu SP, Hsu CY (2014) Venous ligation: a novel strategy for glans enhancement in penile prosthesis implantation. BioMed research international 3: 1-7

32. Vale JA, Feneley MR, Lees WR, Kirby RS (1995) Venous leak surgery: long-term follow-up of patients undergoing excision and ligation of the deep dorsal vein of the penis. Br J Urol 76: 192-195. [Crossref]

33. Chen SC, Hsieh CH, Hsu GL, Wang CJ, Wen HS, et al. (2005) The progression of the penile vein: could it be recurrent? J Androl 26: 53-60. [Crossref]
34. Zhang B, Chen J, Xiao H, Zhang Y, Cai L, et al. (2009) Treatment of penile deep dorsa venous leakage of erectile dysfunction by embedding the deep dorsal vein of the penis: a single center experience with 17 patients. $J$ Sex Med 6: 1467-1473. [Crossref]

35. Kutlu R (2009) Deep dorsal vein embolization with N-butyl-2-cyanoacrylate and lipiodol mixture in venogenic erectile dysfunction: early and late results. radiology and oncology 43: 1-7

36. Miwa Y, Shioyama R, Itou Y, Kanamaru H, Okada K (2001) Pelvic venoablation with ethanol for the treatment of erectile dysfunction due to veno-occlusive dysfunction. Urology 58: 76-79.

37. Nakata M, Takashima S, Kaminou T, Koda Y, Morimoto A, et al. (2000) Embolotherapy for venous impotence: use of ethanol. J Vasc Interv Radiol 11: 1053-1057. [Crossref]

38. Peaykircioaylu L, Tekin I, Boyvat F, Karabulut A, Ozkardeay H (2000) Embolization of the deep dorsal vein for the treatment of erectile impotence due to veno-occlusive dysfunction. J Urol 163: 472-475. [Crossref]

39. Sangiorgi G, Colantonio R, Antonini G, Savino A, Sperandio M (2016) Percutaneous intervention therapy for vascular erectile dysfunction. G Ital Cardiol (Rome) 17: 12S121

40. Schild HH, Muller SC, Mildenberger P, Strunk H, Kaltenborn H, et al. (1993) Percutaneous penile venoablation for treatment of impotence. Cardiovasc Intervent Radiol 16: 280-286. [Crossref]

41. Schild HH, Muller SC (1993) Retrograde penile venoablation. Ann Acad Med Singapore 22: 675-678. [Crossref]

42. Schild HH, Muller SC, Hermann M, Kaltenborn H, Kern M, et al. (1993) Penile venous outflow occlusion: a comparison of erectile function and cavernosometry before and after percutaneous interventions. Rofo 158: 59-61.

43. Schild HH, Müller SC, Mildenberger P, Strunk H, Thelen M (1993) Retrograde venous occlusion--therapy of impotence of venous origin]. Rofo 158: 238-241. [Crossref]

44. Campbell B (2006) Varicose veins and their management. BMJ 333: 287-292. [Crossref]

45. Redondo P, Cabrera J (2005) Microfoam sclerotherapy. Semin Cutan Med Surg 24 175-183. [Crossref]

46. Herwig R, Margreiter M, Kuehhas F (2012) c22 pelvic venoablation for the treatment of erectile dysfunction caused by venous leakage. European Urology Supplements 11: $1-87$.

47. Carrino M, Pucci P, Chiancone F, Battaglia G, Meccariello C (2016. Embolization of the deep dorsal vein using aethoxysklerol in the treatment of erectole dysfunction resulting from venous leakage. Analysis of our experience with 171 patients. XXIII Congresso Nationale Auro.it 13: 1-12.

48. Xu, CC, Pan YN, Tang YF, Zhang J, et al. (2017) Comprehensive assessment of cavernosography with 320-row dynamic volume CT versus conventional cavernosography in erectile dysfunction patients caused by venous leakage. Biosci Rep 37: $1-12$

49. Keller JJ, Lin HC (2012) Haemorrhoids are associated with erectile dysfunction: a population-based study. Int J Androl 35: 867-872. [Crossref]

50. Pilkington, S. A., A. C. Bateman, S. Wombwell, and R. Miller. 2000. Anatomical basis for impotence following haemorrhoid sclerotherapy. Ann R Coll Surg Engl 82: 303306

51. Rebonato A, Maiettini D, Ceccherini C, Nuti A, Sanguinetti F (2017. Endovascular treatment of recurrent erectile dysfunction due to venous occlusive disease. Asian $J$ Androl 19: 509-510.

52. Aschenbach R, Steiner T, Kerl MJ, Zangos S, Basche S, et al. (2013) Endovascula embolisation therapy in men with erectile impotence due to veno-occlusive dysfunction. Eur J Radiol 82: 504-507.

53. Rebonato A, Auci A, Sanguinetti F, Maiettini D, Rossi M, et al. (2014) Embolization of the periprostatic venous plexus for erectile dysfunction resulting from venous leakage. J Vasc Interv Radiol 25: 866-872.

Copyright: (C2018 Herwig R. This is an open-access article distributed under the terms of the Creative Commons Attribution License, which permits unrestricted use, distribution, and reproduction in any medium, provided the original author and source are credited. 